\title{
FTIR-spectral analysis of two photosynthetic hydrogen-producing strains and their extracellular polymeric substances
}

\author{
Guo-Ping Sheng $\cdot$ Han-Qing Yu $\cdot$ Cheng-Ming Wang
}

Published online: 3 August 2006

(C) Springer-Verlag 2006

The online version of the original article can be found at: http://dx.doi. org/10.1007/s00253-006-0442-2.

G.-P. Sheng $\cdot$ H.-Q. Yu $(\bowtie)$

Laboratory of Environmental Biotechnology,

School of Chemistry,

University of Science and Technology of China,

Hefei, 230026, People's Republic of China

e-mail: hqyu@ustc.edu.cn

C.-M. Wang

Hefei National Laboratory for Physical Sciences of Microscale,

University of Science and Technology of China,

Heife, 230026, People's Republic of China
Unfortunately, the title of the article was incorrect. The correct title is given above. 